\title{
The Importance of Superplastizer Dosage in the Mix Design of Lightweight Aggregate Concrete Reinforced With Plypropylene Fiber
}

\author{
Payam Shafigh ${ }^{1, a}$, Javad Yahaghi² \\ ${ }^{1}$ Department of Building Surveying, Faculty of Built Environment, University of Malaya, 50603 Kuala Lumpur, Malaysia \\ ${ }^{2}$ Department of Civil Engineering, Faculty of Engineering, University Tenaga Nasional, Jalan IKRAM-UNITEN, 43000 Kajang, Selangor, \\ Malaysia
}

\begin{abstract}
This paper reports the results of a study conducted to investigate the effect of superplasticizer (SP) dosage on the slump, density, compressive strength and splitting tensile strength under different curing conditions of a lightweight aggregate concrete reinforced with polypropylene (PP) fiber. The lightweight aggregate used in this study was oil palm shell, which is an agricultural solid waste, originating from the palm oil industry. The results indicated that an increase in superplasticizer increased the workability, however, all the mechanical properties declined significantly. The reduction in the 28-day compressive and splitting tensile strengths was about 14 . This study showed that although additional SP can improve the workability of the concrete, it may have a negative effect on the other properties of concrete. Therefore, the SP dosage in concrete mixtures containing PP fiber should be limited to a certain amount.
\end{abstract}

\section{Introduction}

Since the majority of natural resources are limited, any effort to use waste and recycled materials in concrete production can reduce resource depletion and promote energy conservation in the construction sector [1]. Oil palm shell (OPS) is an agricultural waste product obtained from the processing of palm oil and is available in large quantities in the tropical regions of the world, most especially in Africa, Asia and America [2]. Although generally, the mechanical properties of OPS concrete are less than those for ordinary concrete, one way to improve the mechanical properties of OPS concrete is by using fibers. Polypropylene (PP) fibers are mainly used to improve the ductility, toughness and impact resistance of concrete. Although they are not expected to increase the concrete strength, however, the addition of PP fiber greatly decreases the workability of concrete [3], which restricts the quantity of PP fiber [4], [5].

Superplasticizer (SP) is used as a dispersant to avoid particle segregation (gravel, coarse and fine sand), and to improve the flow characteristics of concrete and enhance the fluidity of the fresh concrete without adding water, with respect to their surfactant properties. This effect considerably improves the hardening performance of concrete [6]-[8]. The strength of concrete increased when the water to cement ratio decreased. However, the working mechanism lacks a full understanding, revealing, in certain cases, cement-superplasticizer incompatibilities [9]. The addition of superplasticizer during transport is a new development within the industry and the addition of

\footnotetext{
${ }^{a}$ Corresponding author: pshafigh@gmail.com
}

admixture for slump management systems allow concrete producers to maintain slump until discharge.

The main objective of this paper is to investigate the effect of superplasticizer dosage on the fresh and hardened properties of polypropylene reinforced oil palm shell concrete. The objective was achieved by testing 66 specimens for two mix designs.

\section{Experimental details}

\subsection{Materials}

The materials used in this study were ASTM type I ordinary Portland cement, and local mining sand with a specific gravity, water absorption, fineness modulus and maximum grain size of $2.68,0.94 \%, 2.65$, and $4.75 \mathrm{~mm}$, respectively. OPS in a saturated surface dry condition, with a maximum size of $12.5 \mathrm{~mm}$, specific gravity, compacted bulk density and $24 \mathrm{~h}$ water absorption of $1.22,673 \mathrm{~kg} / \mathrm{m} 3$, and $21 \%$, respectively, was used as lightweight aggregate. The PP fiber used in this study had a length of $12 \mathrm{~mm}$ and specific gravity of $0.90 \mathrm{~kg} / \mathrm{dm}^{3}$. The SP Sika ViscoCrete-15RM, supplied from Sika used in this study was, is in conformity with EN 934-2. It was used as $1 \%$ and $1.5 \%$ of cement weight.

\subsection{Mix proportions}

The mix design used in this study is shown in Table 1. Typically, the PP fiber volume used in concrete is in the 
range of $0.1 \%-0.3 \%$. Because of the decreased workability of concrete caused by the addition of PP fiber, a low volume fraction of fiber was used in this study. The volume fraction of PP fiber in OPS concrete was $0.2 \%$.

Table 1. Mix proportions of concrete in one batch.

\begin{tabular}{|c|c|c|}
\hline Mix code & L1 & L2 \\
\hline Cement (kg) & 32.70 & 32.70 \\
\hline Water (kg) & 11.14 & 11.14 \\
\hline Sand (kg) & 55.00 & 55.00 \\
\hline Granite (kg) & 24.20 & 24.20 \\
\hline OPS (kg) & 16.30 & 16.30 \\
\hline Fiber Volume (\%) & 0.2 & 0.2 \\
\hline SP (\%) & 1 & 1.5 \\
\hline
\end{tabular}

\subsection{Test method and curing regimes}

All the materials except the water and SP were put into a mixer and mixed for $3 \mathrm{~min} ; 70 \%$ of the mixing water together with SP was added and mixed for $5 \mathrm{~min}$, then, the remaining water was added and mixed for another 10 minutes. At the end of this time, PP fiber were spread in the mixer. The mixture with fiber was mixed for a further 5 min. Before casting the samples, the slump test of the mixture was performed. The concrete specimens were cast in steel molds and compacted on a vibration table. For each mixture, $(24)$ cubes $(100 \times 100 \times 100 \mathrm{~mm} 3)$ were used for the measuring of the compressive strength at 1,3 and 28 days; 6 cylinders of $100 \mathrm{~mm}$ diameter and $200 \mathrm{~mm}$ height and 3 prisms of dimension $100 \mathrm{~mm} \times 100$ $\mathrm{mm} \times 500 \mathrm{~mm}$ for determination of the indirect tensile strength and flexural strength, respectively. As can be seen in figure 1 , adding $0.05 \%$ more SP to mix L1 caused water bleeding after the same vibration process. The specimens were demolded one day after casting. For determining the effect of the curing environment on the 28-day compressive strength of OPS concrete, the specimens were cured under three types of curing condition as given below:

$\mathrm{NC}$ : Specimens were immersed in water at $23 \pm 3{ }^{\circ} \mathrm{C}$ until the age of testing.

7DC: Curing in water for 6 days after demolding and then air cured in a laboratory environment with a $\mathrm{RH} \%$ of $70 \pm 10$ and a temperature of $29 \pm 3{ }^{\circ} \mathrm{C}$.

AC: Specimens were kept in a lab environment after demolding.
Figure 1. Water bleeding after vibration in mix L2 (right side specimen).

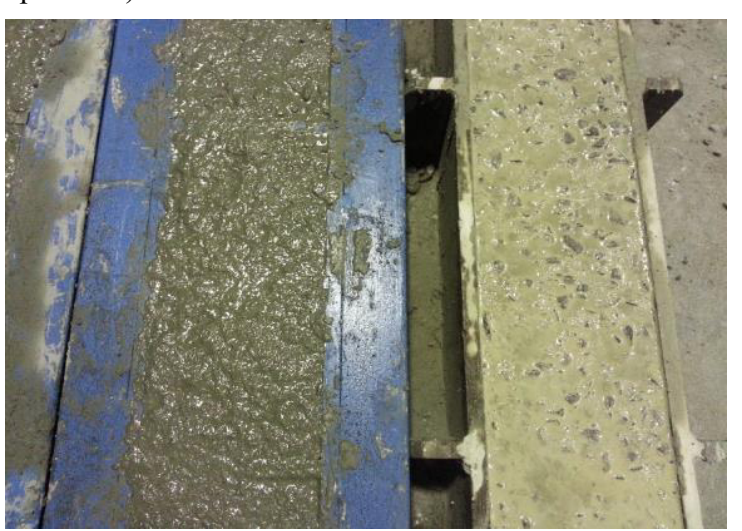

\section{Results and discussion}

\subsection{Workability}

The slump value of mix L1, before adding PP fiber, was about $90 \mathrm{~mm}$. However, after adding the fiber, the slump value was $35 \mathrm{~mm}$, which is considered to be a low slump value. Previous studies [10], [11] show that the addition of fiber reduces the slump value. One of the methods to increase the workability of concrete is the use of SP in the concrete mixture. Therefore, in this study, $50 \%$ more SP was added to the L1 mix (mix L2) to consider the effectiveness of SP on the workability and hardened properties of the lightweight concrete. It was observed that by increasing the SP content from $1 \%$ to $1.5 \%$ the slump value increased by about $20 \%$.

\subsection{Density}

Four types of density, namely, demoulded (De), 28-day air-dry (AD), saturated (Sa) and oven-dry (OD) densities were measured for both mixes. The 28-days air-dry density and oven-dry density of L1 and L2 mixes were around $2050 \mathrm{~kg} / \mathrm{m} 3$ and $1997 \mathrm{~kg} / \mathrm{m} 3$. The demolded density and 28-day water cured density of L2 mix were $1.03 \%$ and $0.77 \%$, respectively more than that of $\mathrm{L} 1 \mathrm{mix}$. Figure 2 shows the relationship between the mixes and different densities.

Figure 2. Densities of concrete mixtures.

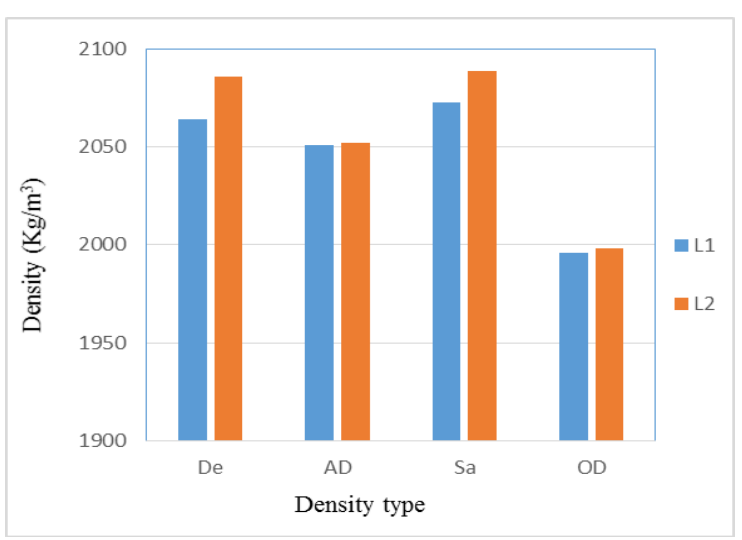




\subsection{Compressive strength}

\subsubsection{Continuously moist curing}

As can be seen from Table 2, the compressive strength of L2 mix decreased at all ages with an addition in SP. Increasing the SP ratio from $1 \%$ to $1.5 \%$ decreased the compressive strength by about $26 \%$ at 1 -day age, $14 \%$ at 3 -day age, $16 \%$ at 7 -day age and $14 \%$ at 28 -day age, respectively. A comparison of the strength at the early and later ages indicate that the rate of strength development was greater as the age increased, especially for concretes with lower SP content. This phenomenon can be observed when we see the percentages of the 28day compressive strength for each age in Table 2. Figure 3 presents the compressive strength development for mix L1 and mix L2.

Table 2. Mix proportions of concrete in one batch.

\begin{tabular}{|c|c|c|}
\hline Mix code & L1 & L2 \\
\hline 1 day & $18.89(57 \%)$ & $14.01(63 \%)$ \\
\hline 3 days & $32.68(74 \%)$ & $28.28(74 \%)$ \\
\hline 7 days & $39.22(89 \%)$ & $33.06(87 \%)$ \\
\hline 28 days & 44.16 & 38.15 \\
\hline
\end{tabular}

*The data in parentheses are the percentage of 28-day compressive strength

Figure 3. Development of compressive strength.

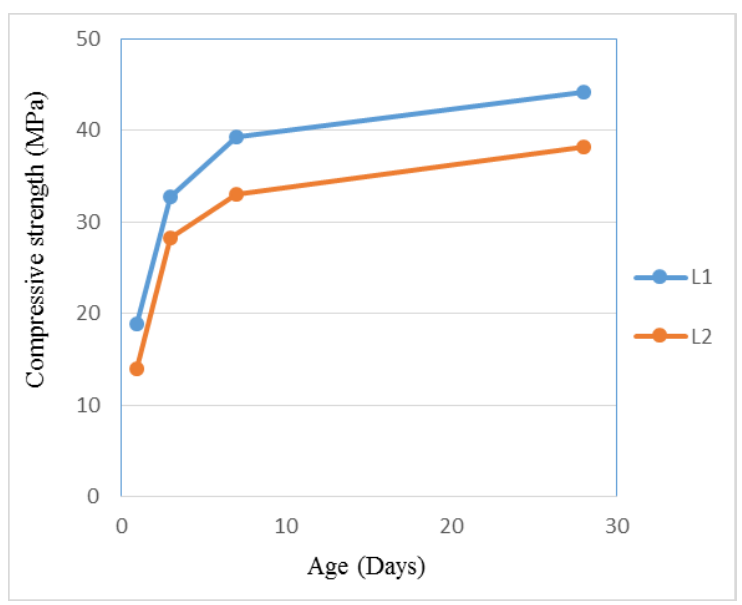

\subsubsection{Effect of curing condition}

Curing requires a satisfactory moisture content and temperature to be maintained in concrete during its early stages so that the desired properties may develop [12]. Figure 4 illustrates the 28-day compressive strength of specimens in three different curing conditions; continuous curing (NC), 7 days moist curing (7DC) and no curing in the lab environment (AC). It can be seen that the order for the strength of concrete was 7DC $>\mathrm{NC}>$ AC. The compressive strength loss for 28-day of samples under $\mathrm{AC}$ curing compared to $\mathrm{NC}$ curing for mixes L1 and L2 was about $8 \%$ and $7 \%$, respectively; the increase for the short time curing period (7DC) was about $2 \%$ and $6 \%$, respectively. As can be seen from this figure, with additional SP the 28-day compressive strength in three different curing conditions of $\mathrm{NC}, 7 \mathrm{DC}$ and $\mathrm{AC}, 14 \%$, $12 \%$ and $13 \%$ decreased respectively.

Figure 4. Development of compressive strength.

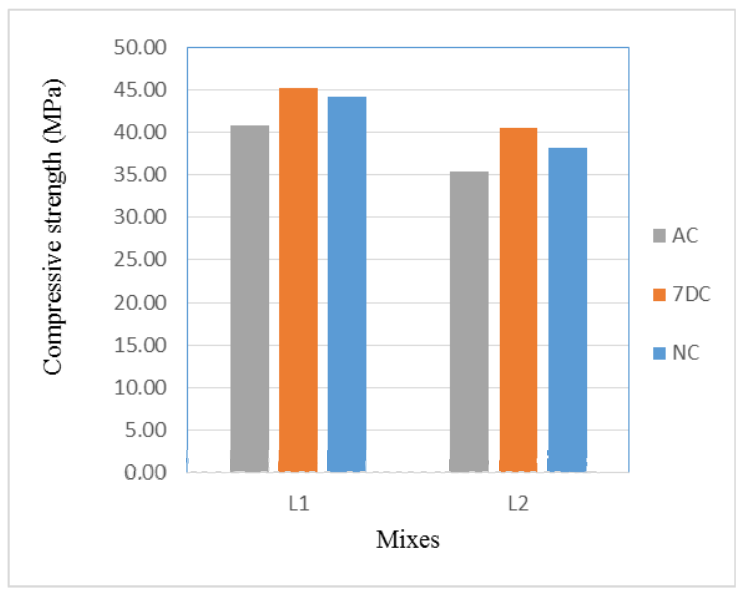

\subsection{Splitting tensile strength}

\subsubsection{Continuously moist curing}

When the SP increased 50\%, the 28-day splitting tensile strength $14 \%$ decreased from 3.71 to $3.176 \mathrm{MPa}$. It was reported that the 28-day splitting tensile strength in moist curing is in the range of 1.9-2.41 MPa, that is, about 6$10 \%$ of the corresponding cube compressive strength. In this study, the splitting tensile strength for mix L1 and mix L2 was about $8.4 \%$ and $8.3 \%$ of the compressive strength, respectively. This shows that the SP obviously did not change the tensile to compressive strength ratio. Generally, the splitting tensile strength of concrete is 8$14 \%$ of the compressive strength. Figure 5 shows the relationship between the splitting tensile strength and the SP volume.

Figure 5. Effect of curing conditions on splitting tensile strength.

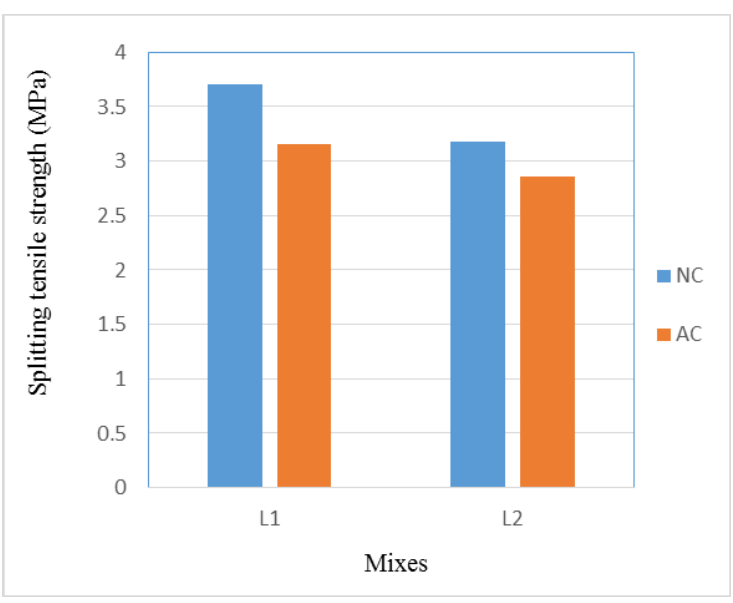




\subsubsection{Effect of curing condition}

Figure 5 illustrates the 28-day splitting tensile strength of specimens in two different curing conditions: continuous curing (NC) and no curing in lab environment (AC). It can be seen that the order of the strength of concrete was $\mathrm{NC}>\mathrm{AC}$. The splitting tensile strength loss for 28-day samples under AC compared to NC for mixes L1 and L2 was about $15 \%$ and $10 \%$, respectively.

\section{Conclusions}

The aim of this study was to investigate the effect of adding SP on some engineering properties of OPS-PP fiber lightweight concrete. The test results showed that by increasing the SP content from $1 \%$ to $1.5 \%$ the workability increased about $20 \%$ but the oven and air-dry densities were not affected. The compressive strength of concrete decrease at all ages. In comparing the air-curing regime (AC) and the 7 days curing regime (7DC) with the continuous curing regime (NC), the addition of SP ratio did not affect the strength loss rate. The splitting tensile strength also decreased from 3.71 to $3.18 \mathrm{MPa}$. In general, it can be concluded that although additional SP may improve the slump value of concrete containing PP fiber, it may have a negative effect on the other properties.

\section{References}

1. P. Shafigh, M. Z. Jumaat, H. Bin Mahmud, and U. J. Alengaram, Constr. Build. Mater. 40, 231 (2013)

2. E. A. Olanipekun, K. O. Olusola, and O. Ata, Build. Environ., vol. 41, 297 (2006)

3. H. Mazaheripour, S. Ghanbarpour, S. H. Mirmoradi, and I. Hosseinpour, Constr. Build. Mater. 25, 351 (2011)

4. P. S. Song, S. Hwang, and B. C. Sheu, Cem. Concr. Res. 35, 1546 (2005)

5. N. Banthia and R. Gupta, Cem. Concr. Res. 36, 1263(2006)

6. S. M. a. El-Gamal, F. M. Al-Nowaiser, and A. O. AlBaity, J. Adv. Res. 3, 119 (2012)

7. E. Tkaczewska, Constr. Build. Mater. 70, 388 (2014)

8. V. Morin, F. Cohen Tenoudji, A. Feylessoufi, and P. Richard, Cem. Concr. Res. 31, 63 (2001)

9. V. S. Ramachandran, Concrete Admixtures Handbook, 2nd Ed.: Properties, Science and Technology. (1995)

10. B. Chen and J. Liu, Cem. Concr. Res. 35, 913 (2005)

11. P. Shafigh, H. Mahmud, and M. Z. Jumaat, Mater. Des. 32, 3926 (2011)

12. ACI Committee 308, Proposed ACI standard:Standard Practice for Making and Curing Concrete Test Specimens in the Laboratory, (1980) 